\title{
EDUCAÇÃO PARA O EMPREENDEDORISMO COMO ESTRATÉGIA PARA FORMAR UM TRABALHADOR DE NOVO TIPO
}

\author{
EDUCATION TO ENTREPRENEURSHIP AS A STRATEGY TO BUILD THE \\ NEW KIND OF WORKER
}

\author{
Marival Coan ${ }^{1}$
}

\section{RESUMO}

O empreendedorismo e sua vinculação ao campo educacional ganharam relevo nos últimos tempos. Prova cabal dessa afirmação é o expressivo aumento de pesquisas e desenvolvimento de projetos que têm por objetivo educar para o empreendedorismo e formar um trabalhador de novo tipo, capaz de autoproduzir sua própria existência. A formação do trabalhador/empreendedor com perfil e espírito inovador, criativo e proativo, capaz de criar seu próprio negócio ou agir como se fosse dono da organização, preconiza o papel social do indivíduo abstraído das determinações estruturais, notadamente da ordem econômica vigente, a capitalista. Essa proposição precisa ser questionada: afinal, 0 que significa educar para 0 empreendedorismo e a quem interessa esta proposição? Centrado no referencial do materialismo histórico e dialético, o presente texto procura analisar como a elaboração desta ideologia do "homem empreendedor" foi e está sendo instituída no espaço escolar, além de apresentar e analisar tal formulação, buscando o significado implícito da necessidade de se educar para o empreendedorismo.

Palavras-chave: Trabalho - Educação - Empreendedorismo - Formação do trabalhador.

\begin{abstract}
Entrepreneurship and its link in the education field has had increased significance in the last years, with the ample proof through the expressive growth of research and project development aiming at educating towards entrepreneurship and training a new kind of worker, the one who is able to selfproduce its own existence. Training of the worker/entrepreneur with the innovative, creative and proactive profile and spirit, able to create its own business or to act as if the owner of the organization establishes the social role of the individual that is abstracted from structural determinations, especially in the current capitalist economic order. This approach needs to be questioned: what does it mean, after all, to educate towards entrepreneurship and to whom this approach matters? Centered in the historical materialism and dialectic referential, this text tries to analyze how the elaboration of this entire ideology of the entrepreneur being has been and is being instituted in the education setting, as well as presenting and analyzing this formulation, in the search of the implicit meaning of the need to educate towards entrepreneurship.
\end{abstract}


Keywords: Work - Education - Entrepreneurship - Worker training.

\section{INTRODUÇÃO}

A necessidade de formar pessoas com espírito empreendedor, principalmente por meio da educação escolar em todos os níveis e modalidades de ensino, vem se difundindo muito rapidamente, tanto por meio de pesquisas, como por meio de realização de projetos práticos que legitimam o modo capitalista de produção e intentam atender às suas demandas. Por conseguinte, o presente texto é um esforço na perspectiva de compreender todo esse movimento e provocar a reflexão acerca das implicações trazidas pela absorção acrítica das proposições que se articulam em torno do tema do empreendedorismo, tendo como referencial metodológico os princípios do materialismo histórico e dialético. Esse arcabouço teórico oferece os elementos necessários à realização da crítica à educação para o empreendedorismo como movimento edificado sobre os princípios das relações sociais capitalistas e, portanto, voltados para sua legitimação; uma vez que tal educação se serve de referenciais e pressupostos reacionários às lutas dos trabalhadores e contribui para a internalização da ideologia dominante e a consequente alienação humana.

Nesse contexto, o espaço escolar é disputado como lócus para formar um trabalhador de novo tipo, convencido de estar apto a enfrentar os desafios do atual mercado de trabalho vendendo sua força de trabalho sob diversos moldes, quer seja prestando serviços, fazendo consultorias, realizando trabalho terceirizado, temporário, a domicílio, subcontratado, quer seja com bolsas de estudo, estágio ou arranjos flexíveis e precários similares.

O discurso da necessidade de se educar para o empreendedorismo ganhou relevo nos anos de 1990, quando várias propostas foram apresentadas para combater os problemas decorrentes do desemprego que atingiu sobremaneira os jovens. O diploma não é mais garantia de colocação profissional; coadunado a ele deve haver também habilidades e competências empreendedoras. Os concluintes do Ensino Médio regular, profissional ou 
universitário saem em busca do primeiro emprego, mas nesta empreitada percebem que concorrem com um imenso contingente de desempregados, e quando encontram uma oferta são frustrados pelo fato de não possuírem os requisitos exigidos pelo posto de trabalho, principalmente o da experiência profissional.

Há evidências de que o empreendedorismo foi transformado em palavra de ordem. Seus defensores apregoam que não se pode mais pensar em preparar as novas gerações para um futuro de emprego formal e garantias trabalhistas que estão em extinção. O discurso corrente é o de que se tornou necessário ao trabalhador estar provido de novas competências e habilidades para que consiga adquirir conhecimentos que gerem valor. Diversos autores defendem a ideia de que o trabalhador precisa descobrir suas características empreendedoras, arregaçar as mangas e buscar solução para seus problemas. Para eles, quem tem "espírito empreendedor" tem iniciativa, autoconfiança, se arrisca e aceita as consequências desse risco, pois tem o perfil de um destemido e fará tudo para não fracassar. Essa postura, segundo os gurus do empreendedorismo, Ihe permitirá tomar decisões responsáveis. O empreendedor sabe-se timoneiro de seu próprio destino e capaz de controlar situações adversas, aproveitá-las, liderar equipe e, com persistência e motivação, sabe obter resultados.

O discurso sobre o empreendedorismo se tornou lugar comum e permeia as propostas e políticas para a formação dos trabalhadores, principalmente da juventude, em diversos continentes. Na América Latina, a manifestação de maior abrangência em prol do empreendedorismo na educação foi feita pela Oficina Regional de Educação para América Latina e o Caribe (OREALC) da Organização das Nações Unidas para a Educação, a Ciência e a Cultura (UNESCO), anunciada no Projeto Regional de Educação para a América Latina e o Caribe - PRELAC ${ }^{2}$ que incluiu um quinto pilar, o "aprender a empreender" aos quatro estabelecidos, em 1996, pelo Relatório Delors da Comissão para a Educação no século XXI da Organização das Nações Unidas para a Educação, a Ciência e a Cultura (DELORS, 1999).

Ao acrescentar o "aprender a empreender" como pilar da política educacional, UNESCO (1998) procura estabelecê-lo como eixo da educação, atrelando-o à missão de gerar alternativas para o desemprego de modo a 
assegurar que mesmo em tempos de crise a humanidade mantenha a produção coletiva de riquezas, preservando a apropriação privada.

Entende-se que a proposição de se educar para 0 empreendedorismo carece de análises mais acuradas para se compreender a popularidade adquirida pelo tema na área da educação, como atitude a ser formada nos trabalhadores para enfrentarem os desafios atuais, principalmente no que diz respeito ao trabalho e à empregabilidade. $O$ foco desse texto é o de analisar o empreendedorismo na educação, em especial as propostas da Pedagogia Empreendedora, a partir dos fundamentos do materialismo histórico. Para tanto, apóia-se em pesquisas que abordam criticamente o tema e problematizam a proposição que sustenta a necessidade de se educar para o empreendedorismo, a qual vem se constituindo num eixo das propostas da formação dos trabalhadores, especialmente no ensino médio e na educação profissional e tecnológica.

\section{RAÍZES HISTÓRICAS DO EMPREENDEDORISMO E SUA GÊNESE LIBERAL}

A palavra empreendedorismo deriva do termo francês entrepreneur, traduzido para o inglês como intrepreneurship, e remonta ao século XV, quando era usado para referir-se aos "homens de negócios". O termo ganhou maior visibilidade nas obras de Cantillon (2002) e Say (1983) que, a partir da consolidação da sociedade capitalista, relacionaram a figura do empreendedor ao empresário. Richard Cantillon (1680-1734), considerado o precursor do empreendedorismo, preocupava-se com os riscos e as incertezas do processo de acumular riquezas, notadamente na obra Ensaio sobre a natureza do comércio em geral (2002). Sua contribuição em estabelecer os fundamentos do empreendedorismo, bem como o papel do empreendedor ${ }^{3}$ na economia, está posta de modo explícito na primeira parte de seu ensaio, de modo especial o capítulo XIII, em que descreve quem são os empreendedores e como se arriscam na compra e na venda em busca do lucro. O empreendedor deve suportar o jogo do mercado que é deveras incerto ${ }^{4}$, no qual ele pode ganhar ou perder. Se for mal sucedido, poderá passar necessidades e até ir à falência.

Cantillon (2002) ressalta que os riscos e incertezas fazem parte da 
vida de todos os que precisam trabalhar para viver. Todos os que não são príncipes ou proprietários de terras são dependentes e podem ser divididos em duas classes: os que vivem de salários (como os generais que recebem soldos, o cortesão que tem pensão, o criado que recebe salário) e os empresários. Os empresários também vivem de um salário, porém, incerto. $O$ autor entendia que a terra era o centro da produção da existência, por isso considerava os proprietários de enormes quantias de terras a serem arrendadas os únicos indivíduos realmente independentes, os demais seriam todos dependentes.

Outra definição para o empreendedorismo foi apresentada por JeanBaptiste Say (1767-1832) para quem empreendedor é o principal responsável pelo desenvolvimento econômico que resultava, em sua concepção, da criação de novos empreendimentos. Árduo defensor do pensamento liberal, Say se entusiasmava com o progresso econômico trazido pela revolução industrial e por ver o Estado monárquico, preocupado em tributar e gerar moedas, ruir por meio de grandes convulsões, abrindo espaços a um futuro melhor. A marcha do pensamento liberal em curso, da livre iniciativa de pessoas e nações, da concorrência, dava-lhe esperanças.

Os conceitos de empresário, capitalista, investidor, operário foram trabalhados pelo autor com uma conceituação própria, e o empreendedor, para Say, era o empresário industrial, aquele que é capaz de colocar a teoria na prática. Considerava que empreender capitais, na perspectiva da acumulação, era muito salutar e a ninguém deveria amedrontar, uma vez que o próprio curso da natureza tenderia a reparti-los. Além disso, a acumulação fazia crescer o conjunto de capitais de um país. Nessa perspectiva, o direito à propriedade precisava ser preservado, "como o mais poderoso encorajamento à multiplicação das riquezas" (Say, 1983, p. 133). O autor também acreditava na capacidade de aplicação dos talentos individuais e na autorregulação dos mercados, uma vez que "um tipo de produção raramente ultrapassaria os demais, e seus produtos seriam raramente aviltados se sempre deixassem todos à sua inteira liberdade" (Say, 1983, p. 140). Outrossim, o crescimento de um setor econômico contribui para o crescimento dos demais, pois "a prosperidade de uma espécie de indústria favorece a prosperidade de todas as outras" (Say, 1983, p.140). É nesse processo que o homem talentoso se revela. Não basta ter talentos - lembra o autor - é necessária a existência dos 
meios para exercê-los.

Say formulou a ideia - conhecida como "Lei de Say" - de que numa economia mercantil o objetivo do produtor é trocar as mercadorias por ele produzidas por outras mercadorias; assim, o valor da produção de um produtor qualquer é igual ao valor de sua demanda por outras mercadorias. Desconsiderou, dessa forma, que "numa economia mercantil" a produção destina-se à venda e não ao simples autoconsumo. $O$ autor postulava ainda $a$ ideia de que a produção gera sua própria demanda, afirmando não haver restrição de demanda para a contínua expansão da economia (COAN, 2011).

Além da fundamentação liberal, outro traço comum entre as concepções de Cantillon e Say, tomados como autores basilares do empreendedorismo, é que ambos consideravam os empreendedores como pessoas que corriam riscos, posto que investiam seus próprios recursos, sempre na perspectiva de ganharem mais. Compravam matéria-prima por um determinado preço, transformavam-na em produtos para depois revender. Deriva desse fato a compreensão do empreendedor como aquele que aproveita as oportunidades na perspectiva de ganhar mais do que investiu, porém, tem que correr os riscos inerentes a esse jogo. Esses autores formularam suas ideias no início do desenvolvimento da sociedade capitalista, entre os fins do século XVII e início do século XIX, momento em que a economia política ainda não havia recebido as críticas mais contundentes, o que aconteceu pouco tempo depois, a partir da contribuição de Karl Marx (2003) e de outros autores marxistas. Marx, por exemplo, criticou a concepção da lei da oferta e procura de Say, pois a mesma mascara a teoria do valor.

No século $X X$, o empreendedor passou a ser alvo de estudos de outros campos do saber, como a Administração, a Psicologia, a Sociologia, que atribuíram novos significados ao empreendedorismo e enalteceram o comportamento empreendedor dos indivíduos. A partir dos anos de 1980, houve grande expansão do empreendedorismo no campo educacional com o desenvolvimento de várias pesquisas (DRUCKER, 1986; FILION, 1999) em diversos países (Estados Unidos, Canadá, França), principalmente nas áreas das ciências humanas e gerenciais. Essas pesquisas tratavam de temas como: características comportamentais de empreendedores, educação empreendedora, pesquisa empreendedora, pedagogia e cultura 
empreendedora, empreendedorismo e sociedade, empreendedorismo e pequenos negócios, novas oportunidades, desenvolvimento e gerenciamento de negócios, intraempreendedorismo, autoemprego, entre outros. Eram estudos direcionados à busca de estratégias para garantir o sucesso dos novos empreendimentos, acentuando a relevância da articulação entre escola/universidade e empresas.

No Brasil, a educação para o empreendedorismo, na década de 1980, ganha adesão inicialmente no ensino superior, alastrando-se, lentamente, para os outros níveis e modalidades de ensino. O ensino de empreendedorismo iniciou-se na Escola de Administração de Empresas da Fundação Getúlio Vargas, em São Paulo, em 1981. Em 1984, a Faculdade de Economia, Administração e Contabilidade da USP oferece a disciplina. Também em 1984, foi ministrado o primeiro curso de empreendedorismo em um Departamento de Ciência da Computação da Universidade Federal do Rio Grande do Sul. Em 1993, foi criada uma rede de ensino de empreendedorismo por meio do programa SOFTEX/CNPq (Associação para Promoção da Excelência do Software Brasileiro) com o desenvolvimento de uma metodologia de ensino de empreendedorismo e atingiu mais de 100 departamentos de ensino de informática em 23 estados brasileiros e no Distrito Federal. (Araújo et al 2005).

Em maio de 1992, a Universidade Federal de Santa Catarina UFSC criou uma Escola de Novos Empreendedores - ENE, com a missão de promover ações de intercâmbio com a sociedade que resultassem na criação, no desenvolvimento e na consolidação de uma cultura empreendedora. Em 1998, a ENE lançou o Programa de Empreendedorismo em Educação, direcionado ao ensino fundamental, reunindo profissionais e pesquisadores de múltiplas áreas de conhecimento, docentes e alunos do Curso de PósGraduação em Engenharia de Produção, tendo por foco o empreendedorismo para as crianças. Em 1999, foi criado na UFSC o Programa Engenheiro Empreendedor, com o objetivo de oferecer cursos na área de empreendedorismo e de organizar concursos de planos de negócios para alunos das engenharias. A partir de então, houve expressivo crescimento do ensino do empreendedorismo em diversas Universidades e cursos. Contudo, o grande alarde sobre as façanhas dos empreendedores exitosos convive com o 
silêncio absoluto sobre os casos das falências 5 . A Global Entrepreneurship Monitor (GEM), que há alguns anos vem estudando a atividade empreendedora em cerca de 150 países, inclusive o Brasil, destaca que o empreendedorismo leva muita gente à falência ${ }^{6}$.

\section{EMPREENDEDORISMO NA EDUCAÇÃO PARA FORMAR O TRABALHADOR DE NOVO TIPO}

Na educação básica e profissional o ensino do empreendedorismo está se consolidando, especialmente pela adesão a projetos baseados na pedagogia empreendedora ${ }^{7}$ desenvolvida por Fernando Dolabela $^{8}$, seja como disciplina ou mesmo conhecimento extracurricular transdisciplinar, com presença marcante do Serviço Brasileiro de Apoio às Micro e Pequenas Empresas (SEBRAE), Organizações Não Governamentais (ONG) ou, mesmo, de entidades ligadas à divulgação do empreendedorismo, como a Junior Achievement (JA) e Empresa Junior dentro das escolas.

Também é expressivo o número de pesquisas de mestrado e doutorado que descrevem acerca da necessidade de se educar os trabalhadores para serem empreendedores. Eis alguns exemplos: Pereira (2001) apresenta procedimentos metodológicos para o desenvolvimento e a atualização de habilidades do sujeito empreendedor, notadamente do jovem universitário, que precisa ser formado com uma nova mentalidade para atender e se adequar às mudanças do mundo atual. Miranda (2002) elaborou uma metodologia para introdução do ensino de empreendedorismo nos cursos técnicos de nível médio. Wolf (2004) descreve acerca da aceitação do aprendizado do empreendedorismo como facilitador do sucesso profissional de alunos do ensino médio. Bastos et al (2006) entende que o projeto do empreendedorismo na escola básica como matéria extracurricular, transdisciplinar, permite incorporar ao ensino curricular obrigatório outros conhecimentos que provoquem nos jovens novos comportamentos e novas posturas a partir do ideal empreendedor. Friedlaender (2004) e Santos (2002) reforçam a necessidade de formar para o empreendedorismo, pois 0 empreendedor sabe buscar as oportunidades, tem iniciativa, é persistente e comprometido com seu projeto. Também é exigente consigo mesmo e sabe 
que enfrentará riscos, estabelece e procura cumprir metas, busca informações e sabe utilizá-las, sabe usar a arte da comunicação e persuasão e é independente e autoconfiante ${ }^{9}$.

Entre os diversos autores que sustentam a ideia de educar os atuais e futuros trabalhadores para o empreendedorismo, indubitavelmente, Fernando Dolabela é o que mais se destaca em função das diversas proposições e trabalhos práticos que apresenta e desenvolve, com destaque para a pedagogia empreendedora (DOLABELA, 2003) e oficina do empreendedor (DOLABELA, 1999).

Dolabela organizou vários materiais e atividades para alunos e professores, tais como livros, artigos, cadernos de exercícios, software, seminários, cursos, oficinas. O autor (DOLABELA, 2003) destaca que o mundo atual passa por rápidas e profundas transformações que exigem um novo posicionamento da escola. Nesse contexto, a tarefa da educação empreendedora seria, principalmente, a de fortalecer os valores empreendedores na sociedade, a capacidade individual e coletiva de gerar valores para toda a comunidade, de inovar, de ser autônomo e de buscar a sustentabilidade. A tese do autor é a de que o atual modelo educacional fundamenta-se numa cultura que pretende preparar crianças, jovens e adultos, exclusivamente, para conseguirem um emprego. Contrário a esse modelo, que considera anacrônico, o autor insiste na necessidade de se praticar os princípios do empreendedorismo na escola como um meio para mudar o paradigma educacional. A meta principal da pedagogia empreendedora é inserir o empreendedorismo na educação básica, além de procurar articulá-lo com a construção de tecnologias de desenvolvimento social local sustentável (DOLABELA, 2003).

Diversas entidades e escolas aderiram à proposta de Dolabela, e os dados divulgados por elas mostram que a proposta vem influenciando projetos pedagógicos de diversas escolas, com o apoio de várias secretarias municipais e estaduais de educação e da rede privada de ensino. Relatos, por exemplo, da experiência desenvolvida com alunos do ensino fundamental da Escola Municipal Israel Pinheiro, de Belo Horizonte/MG, mostram como os alunos aprendem desde cedo que empreender pode ser um bom negócio ${ }^{10}$. A instituição investe na pedagogia empreendedora e em sua metodologia para 
inserir o ensino do empreendedorismo na educação básica de crianças, jovens e adultos na perspectiva de fazer com que a educação fortaleça o indivíduo para construir seu próprio futuro. A Prefeitura de Ponta Grossa/PR aderiu à pedagogia empreendedora. $\mathrm{O}$ projeto é desenvolvido em conjunto com a Universidade Tecnológica Federal do Paraná (UTFPR) que oferece a capacitação dos professores. A Secretaria Municipal de Educação de Brazópolis/MG, realizou seminários com seus professores para a adoção da pedagogia empreendedora na rede municipal, inclusive contratou palestras ministradas por Fernando Dolabela.

\section{CRÍTICAS À PEDAGOGIA EMPREENDEDORA}

As formulações que sustentam a necessidade de se educar os adolescentes e jovens trabalhadores para o empreendedorismo, em especial Dolabela (2003) e demais autores que seguem essas orientações, foram alvo de críticas. Nessa perspectiva, Cêa e Luz (2006), Cêa (2007), Souza (2006), Souza (2009) e Coan (2011), por exemplo, afirmam que tal postulado, em especial a formulação da pedagogia empreendedora, coaduna-se com as proposições que visam a ajustar os indivíduos às demandas da sociedade capitalista em tempos de globalização da economia, flexibilização do processo produtivo e novas formas de organizar e gerenciar o trabalho na perspectiva de formar um trabalhador de novo tipo.

Cêa e Luz (2006) consideraram que Dolabela (2003) apresenta a ideia de empreender como sinônimo de produção e distribuição de riquezas, sem a devida análise crítica a respeito das relações capitalistas de produção. Os autores procuram explicitar o princípio liberal embutido na proposta da pedagogia empreendedora, que defende a ideia de que os impulsos egoístas concorrem para o bem comum; bem como revelam que a argumentação e o tom sedutor de tal proposta omitem os elementos materiais necessários à realização dos sonhos. Ou, seja, é uma proposta meramente idealista. Outra crítica incide sobre a adoção feita por Dolabela dos pilares da educação apresentados no Relatório Delors (DELORS, 1999), negligenciando o caráter formativo da educação. A individualização das iniciativas que consiste em jogar para o indivíduo a tarefa de sua autorrealização merece atenção, uma vez que 
se trata de uma ideologia que serve para legitimar a ordem vigente, não tem poder explicativo da realidade, intenta acomodar as pessoas, além de tratar a realidade de forma abstrata. Essa teoria, em síntese, sugere que basta que se tenha um sonho, não interessa qual seja, para que se possa realizá-lo.

Nota-se que Dolabela (2003) apresenta uma proposição de ajustamento dos jovens ao atual modelo socioeconômico, mesmo que aparente sinalizar para a necessidade de rupturas. Além disso, os fundamentos epistêmicos da pedagogia empreendedora são absolutamente frágeis e descontextualizados, a começar pelos conceitos de "capital humano" e "capital social" que são pouco explicados (COAN, 2011).

Drewinski (2009) analisa a proposição do empreendedorismo como forma de combater o desemprego juvenil, apresentada por meio da pedagogia empreendedora de Dolabela (2003) e do Projeto Jovem Empreendedor do governo federal. Sustenta que a formação de empreendedores, por meio dessas propostas, busca produzir o consenso de que seria possível criar alternativas de trabalho e geração de renda e, assim, incluir as pessoas no mercado de trabalho. Esta ideia, apresentada como inovadora, é, de fato, uma proposta conservadora, de mera adaptação dos indivíduos à sociedade.

A educação para o empreendedorismo, segundo Souza (2009), faz parte de um ideário educacional mais amplo, disseminado por organismos multilaterais e por muitos governos, na perspectiva de manutenção da hegemonia capitalista que procura reduzir a educação aos estritos interesses da produção da mais-valia pela exploração do trabalho abstrato. A ideologia imersa nesse ideário consiste em afirmar que, no atual contexto, a integração do Brasil no mercado mundial favoreceria o crescimento econômico e geraria inclusão social por meio de atitudes empreendedoras. A origem do empreendedorismo está relacionada à teoria do capital humano e seus desdobramentos na educação e, na atualidade, os apelos para o empreendedorismo estão associados à crise do emprego formal causada pelo próprio capitalismo. Para Souza (2009), o "aprender a empreender" reduz o trabalho educativo à produção de mais-valia em contexto de crise estrutural; aproxima, dessa forma, a educação ao complexo da alienação, "pois pretende, em vão, adaptar o indivíduo à sociedade capitalista de forma a tentar inutilmente harmonizar os conflitos entre capital e trabalho, ao desconsiderar o 
conteúdo desumano que existe durante a produção de mais-valia" (SOUZA, 2009, p.15).

A formação de jovens e trabalhadores empreendedores é uma proposta organicamente articulada ao projeto histórico do capital. Argumentase que essa orientação, que promete realizar o sonho do sucesso pessoal e profissional, opera no sentido de naturalizar a condição de protagonista do jovem, único responsável por sua sobrevivência e pelo desenvolvimento econômico da coletividade a que pertence, revelando ser este um discurso pragmático e ideológico que reforça o individualismo característico da racionalidade neoliberal, o que permite apresentar as formulações que orbitam em torno da formação dos trabalhadores/ empreendedores como ideologia.

\section{EMPREENDEDORISMO COMO IDEOLOGIA}

Procurou-se apresentar a formação dos trabalhadores para o empreendedorismo como ideologia, tomando-se como referência a compreensão de Marx e Engels e outros marxistas, de modo especial Gramsci (1977, 1979) e Mészáros (2007). Para esses autores, as ideologias são representações da realidade, expressam concepções de mundo que servem à legitimação do status quo e reproduzem a sociabilidade capitalista, de modo que se torna necessário analisá-las para construir formas de resistência e de mudança social.

Marx, na introdução de Contribuição à crítica da economia política (1977) e em A ideologia alemã (2001), Marx e Engels destacam que a ideologia se faz presente na superestrutura da vida social que, por sua vez, encontra sua base na produção da existência. Gramsci $(1977,1979)$ concebe que a ideologia, como a própria vida, é espaço de realização da política e a articula a diversos outros conceitos como senso comum, bom senso e consciência filosófica. Para o autor, o senso comum, difuso e incoerente, poderia ser o início de uma trajetória para se chegar ao senso crítico; porém, a compreensão da realidade simplesmente pelo senso comum é restrita e superficial. Analisar a ideologia imbricada no senso comum é desafio para os que lutam contra a ordem estabelecida nas fileiras da contra-hegemonia, na produção de uma contraideologia em prol de um projeto emancipatório. 
István Mészáros (2007), por sua vez, refuta a tese dos ideólogos do capital que difundem a falácia do fim das ideologias. Discordando veementemente, o autor sustenta que "em nossa sociedade tudo está 'impregnado de ideologia', quer percebamos, quer não" (MÉSZÁROS, 2007, p. 57). Portanto, nesse contexto histórico regido pela perversa lógica da propriedade privada e da cultura liberal, é imprescindível conhecer como a sociedade capitalista opera tentando naturalizar suas contradições, uma vez que apresenta "suas próprias regras de seletividade, preconceito, discriminação e até distorção sistemática como 'normalidade', 'objetividade' e 'imparcialidade científica'” (MÉSZÁROS, 2007, p. 57). Nas sociedades de classe, como é a capitalista, o discurso ideológico é utilizado para levar as pessoas a aceitarem as relações sociais vigentes sem questioná-las.

\section{CONSIDERAÇÕES FINAIS}

Procurou-se apresentar como a necessidade de se formar o homem trabalhador para o empreendedorismo, notadamente por meio da educação escolar, tornou-se evidente nos últimos tempos como estratégia para combater o desemprego, constituindo-se, dessa forma em uma ideologia que, enaltecendo o modo de produção capitalista, intenta moldar os indivíduos à ordem social vigente com a promessa de que, com o desenvolvimento de suas potencialidades empreendedoras, obterão sucesso na vida profissional e pessoal. O discurso sobre o empreendedorismo, embebido de valores liberais, prima por ocultar as causas dos problemas sociais, apresentando-os, inclusive, como desafios a serem superados com iniciativa e proatividade individual. Este discurso aparece justaposto a outros - cidadania ativa, responsabilização, empoderamento, capital social, sociedade do conhecimento - como estratagemas utilizados pelo capital, nos últimos tempos, para educar o consenso, de modo especial, por meio da repolitização da política (NEVES, 2010).

No início do século XXI, observa-se a consolidação e o aprofundamento do projeto burguês de sociedade que propõe políticas com 0 objetivo de "aliviar a pobreza" (SHIROMA; EVANGELISTA, 2005), ao mesmo tempo em que estimula a realização de atividades empreendedoras que 
favorecem a competitividade e o individualismo (valores morais do pensamento liberal clássico). Nesse contexto, ganham evidência os discursos centrados na responsabilidade social, no empreendedorismo voltado para o desenvolvimento de projetos educacionais de viés comunitário que, simultaneamente, despolitizam as relações sociais contraditórias e responsabilizam a pessoa e a comunidade pelas soluções das questões sociais e, concomitantemente, estimulam a competitividade e o individualismo como valor moral. Ou seja, a formação do homem empreendedor se funda no espírito competitivo, mas ao mesmo tempo solidário e preocupado com as questões sociais. É o homem responsável por sua própria produção da existência que age de acordo com as leis do mercado capitalista, capaz de se adaptar ao novo mercado de trabalho flexibilizado, mas, simultaneamente, preocupado com a diminuição da miséria humana.

Isso ajuda a compreender as razões pelas quais os discursos em torno do homem de novo tipo - empreendedor - são mais facilmente absorvidos, uma vez que se utilizam de estratégias para sua disseminação, travestidas de uma série de significados, e a educação para o empreendedorismo acaba sendo assumida como forma de dinamizar a educação e torná-la mais atrativa e atual, capaz de responder às demandas contemporâneas de um mundo marcado por profundas mudanças, que exigem um novo modelo de escola para formar um novo perfil de homem/mulher, um novo perfil de trabalhador(a) - inovador e pró-ativo, capaz de autoproduzir sua existência pela criação de seu próprio posto de trabalho ou dinamizar as empresas/organizações por meio de seus atributos como portador de um perfil empreendedor. Entende-se que essa realidade precisa ser questionada e, como destaca Mészáros (2005), a educação não é um negócio; não é uma mercadoria, é criação. Nesse sentido, a educação deve auxiliar na superação da lógica desumanizadora do capital, que tem no individualismo, no lucro e na competição os seus fundamentos.

\section{REFERÊNCIAS}

ARAÚJO, M. H. et al . O estímulo ao empreendedorismo nos cursos de química: formando químicos empreendedores. Química Nova, São Paulo, vol. 28, suplemento, p. s18-s25, Nov/dez. 2005. 
BASTOS, Adriana Teixeira et al. Empreendedorismo e educação: o caso do Projeto Empreendedorismo na Escola, 2006. Disponível em: <http://www.sebrae.com.br>. Acesso em 02/09/2008.

CANTILLON, Richard. Ensaio sobre a natureza do comércio em geral. Curitiba: Segesta editora, 2002.

CÊA, G. S. dos S.; LUZ, A. S. da. Empreendedorismo e educação: reflexões sobre um velho sonho liberal. Revista Espaço acadêmico, Maringá, n.63, agosto/2006. Disponível em <http://www.espacoacademico.com.br/063/63cealuz.htm> Acesso em 05/09/2006.

CÊA, Geórgia S. dos Santos. Fundamentos da ideia do empreendedorismo e a formação dos trabalhadores. In: CÊA, Geórgia S. dos Santos. 0 estado da arte da formação do trabalhador no Brasil. Cascavel: Edunioeste, 2007.

COAN, Marival. Educação para o empreendedorismo: implicações epistemológicas, políticas e práticas. Tese (Doutorado em educação) Programa de Pós-graduação em Educação, Universidade Federal de Santa Catarina, Florianópolis, 2011.

DELORS, Jaques. Educação: um tesouro a descobrir - Relatório para Unesco da Comissão Internacional sobre Educação para o século XXI. 2. ed. São Paulo: Cortez; Brasília: MEC/UNESCO, 1999.

DOLABELA, Fernando. Oficina do Empreendedor. São Paulo: Cultura, 1999.

. Pedagogia empreendedora - o ensino do empreendedorismo na educação básica voltado para o desenvolvimento sustentável. São Paulo: Editora de Cultura, 2003.

DREWINSKI, Jane Maria de Abreu. Empreendedorismo: o discurso pedagógico no contexto do agravamento do desemprego juvenil. Tese (Doutorado em educação) Programa de Pós-graduação em..., Universidade Federal do Paraná, Curitiba, 2009.

DRUCKER, Peter Ferdinand. Inovação e espírito empreendedor (entrepreneurship): prática e princípios. Tradução de Carlos J. Malferrari. São Paulo: Pioneira, 1986.

FILION, Louis Jacques. Empreendedorismo: empreendedores e proprietáriosgerentes de pequenos negócios. Revista de administração, São Paulo, v. 34, n. 2, p. 05-28, abril/junho, 1999.

FRIEDLAENDER, Gilda Maria Souza. Metodologia de ensino-aprendizagem visando o comportamento empreendedor. 2004, 144f. Tese (Doutorado em Engenharia de Produção) Departamento de Engenharia de Produção e Sistemas, Universidade Federal de Santa Catarina, Florianópolis, 2004. 
GRAMSCI, Antonio. Quaderni del Carcere. Edição crítica do Instituto Gramsci, org. Valentino Gerratana, Torino: ed. Einaudi, 1977.

Os intelectuais e a organização da cultura. 3. ed. Rio de Janeiro:

Civilização Brasileira, 1979.

GRECO et.al. Empreendedorismo no Brasil. Curitiba: IBQP, 2008.

MARX, Karl. Contribuição à crítica da economia política. São Paulo: Martins Fontes, 1977.

2003.

. O Capital. Vol. I, Tomo I e II, Rio de Janeiro: Civilização Brasileira,

MARX, Karl e ENGELS, Friedrich. A Ideologia Alemã. Tradução de Luiz Cláudio de Castro e Costa. 2. ed. São Paulo: Martins Fontes, 2001.

MÉSZÁROS, István. A educação para além do capital. Tradução Isa Tavares. São Paulo: Boitempo, 2005.

. O poder da ideologia. $2^{\mathrm{a}}$ reimpressão. Tradução Paulo Cezar Castanheira, São Paulo: Boitempo, 2007.

MIRANDA, Hamilton José. Elaboração de uma metodologia para introdução do ensino de empreendedorismo nos cursos técnicos de nível médio. 2002, 118 f. Dissertação (Mestrado em Engenharia de Produção) departamento de Engenharia de Produção e Sistemas, Universidade Federal de Santa Catarina, Florianópolis, 2002.

NEVES. Lúcia Maria Wanderley. Direita para o social e esquerda para o capital. São Paulo: Xamã, 2010.

PEREIRA, Sonia Maria. A formação do empreendedor. 191f.. Tese (Doutorado em Engenharia de Produção) - Departamento de Engenharia de Produção e Sistemas, Universidade Federal de Santa Catarina, Florianópolis, 2001.

SANTOS, Lucilaine de Souza. Modelo de implantação de educação para o trabalho: um estudo de caso. 2002, 97f. Dissertação (Mestrado em Engenharia de Produção) Departamento de Engenharia de Produção e Sistemas, Universidade Federal de Santa Catarina, Florianópolis, 2002.

SAY, Jean-Baptiste. Tratado de economia política. Tradução de Balthazar Barbosa Filho. Coleção Os Economistas, São Paulo: Abril Cultural, 1983.

SHIROMA, Eneida Oto e EVANGELISTA, Olinda. Educação para o alívio da pobreza: novo tópico na agenda global. In: Quaestio. Vol.7, nº 2, p. 97-111, 2005. 
SOUZA, Adriano Mohn. Jovens e educação empreendedora: que discurso é esse? 2006, 136 f. Dissertação (Mestrado em Educação) - Universidade Católica de Goiás/GO, 2006.

SOUZA Elaine Constant Pereira de. Mercadores de ilusões: a autoajuda e o empreendedorismo no cotidiano dos professores da rede pública do município do rio de janeiro. 2009226 f. Tese (Doutorado em Políticas Públicas) Programa de Pós-Graduação em Políticas Públicas e Formação Humana da Universidade do Estado do Rio de Janeiro, RJ, 2009.

UNESCO. A UNESCO e a educação na América Latina e Caribe 1987 1997. Santiago do Chile, 1998. Disponível em: <http://unesdoc.unesco.org/images/0011/001128/112847porb.pdf>. Acesso em 15 de setembro de 2008.

. PRELAC, uma trajetória para a educação para todos. Revista PRELAC, ano 1, n.0/agosto de 2004. Santiago do Chile. Disponível em: $<$ http://unesdoc.unesco.org/images/0013/001372/137293por.pdf >. Acesso em 22/09/2010.

WOLF, Sergio Machado. Aceitação do aprendizado do empreendedorismo como facilitador do sucesso profissional expressa por alunos do ensino médio em uma unidade escolar da rede pública catarinense. 2004, $128 \mathrm{f}$. Mestrado (Mestrado em Engenharia de produção) - Departamento de Engenharia de Produção e Sistemas, Universidade Federal de Santa Catarina, Florianópolis, 2004.

\footnotetext{
${ }^{1}$ Licenciado em Filosofia, mestre e doutor em Educação pelo PPGE/UFSC. Professor efetivo do IF-SC. Pesquisador do Gepeto/UFSC. Email.: marival@ifsc.edu.br

${ }^{2}$ O Projeto Regional de Educação para a América Latina e o Caribe - PRELAC é uma declaração de consenso entre os ministros da Educação sobre a situação e a projeção da educação na região, com o slogan "Educação para todos". Foi aprovado em novembro de 2002, em Havana, Cuba.(UNESCO, 2004)
}

3 A tradução brasileira da obra de Cantillon não usa o termo empreendedor ou empreendedorismo. O termo usado na tradução portuguesa da Editora Segesta é "empresário", entendido como os arrendatários de terra, os mercadores, atacadistas, comerciantes, mestres de ofício, entre outros, que levam a cabo um empreendimento. A versão inglesa da obra emprega o termo undertaker que pode ser traduzido como empresário, mas também agente funerário, cangalheiro, empreiteiro. Esta nota tem por objetivo demarcar claramente o sentido do termo empreendedor na compreensão dos economistas, que difere da compreensão dos autores comportamentalistas pelo fato de os economistas articularem a noção de empreendedorismo a negócios, ao passo que os comportamentalistas a relacionam a atitudes. A utilização do termo pelos autores que postulam a educação para o empreendedorismo fica nesse limbo entre empreender um negócio ou empreender iniciativas, de caráter generalizado que acaba por tornar o termo bastante vago e propício a todo tipo de utilização, inclusive de caráter falacioso.

4 Registra-se que na configuração social descrita por Cantillon, o empresário, seja ele o arrendatário, o comerciante, lojista, mestre de ofícios, entre outros, não ocupa lugar de destaque na hierarquia social. Os príncipes, os proprietários de grandes quantias de terras ficavam no topo. Como bem ressalta no final do capítulo XII "É a privação do necessário que 
leva a subsistir, num país, os arrendatários, todo tipo de artesãos, os mercadores, os oficiais, os soldados, os marinheiros, os criados e todas as outras ordens que nele encontram ocupação. Toda gente que trabalha serve apenas ao príncipe e aos proprietários [...]." (CANTILLON, 2002, p. 43).

${ }^{5}$ Tanto em Portugal como no Brasil, os casos de falência dos novos empreendedores são muito altos, ultrapassando os $50 \%$ já nos primeiros anos de existência, o que revela que a míope educação para o empreendedorismo serve muito mais para arruinar a vida das pessoas do que, propriamente, permitir a elas obterem sucesso na sociedade do desemprego (COAN, 2011).

${ }^{6}$ Mais informações em Greco et. al. (2008) e no site da entidade: www.gemconsortium.org.

${ }^{7}$ A pedagogia empreendedora refere-se à proposta concebida e criada por Fernando Dolabela (2003) e que visa a difundir o ensino de empreendedorismo na educação básica, desde a educação infantil até o ensino médio. Atinge, portanto, idades de 4 a 17 anos.

${ }^{8}$ Fernando Celso Dolabela Chagas é graduado pela Universidade Federal de Minas Gerais (UFMG) em Direito e Administração, e Mestre em Administração pela UFMG (1990). É consultor da Confederação Nacional da Indústria - Instituto Euvaldo Lodi (CNI-IEL), do CNPq, da Agência de Educação para o Desenvolvimento (AED) e de dezenas de Universidades.

${ }^{9}$ Um estado da arte mais detalhado da temática pode ser encontrado em Coan (2011).

10 Relatos do boletim interno da escola disponibilizado no site: <http://emipbhte.blogspot.com/>.

RECEBIDO EM: agosto/2013

APROVADO EM: setembro/2013 